\title{
EL «CONTRAINFORME ONAINDÍA»
}

\author{
POR \\ JosÉ LUIS MARTíNEZ SANZ \\ Universidad Complutense
}

\section{ReSUMEN}

Transcripción y estudio del informe realizado por Alberto Onaindía y Zuloaga para intentar justificar que un partido católico, como el PNV, defendiera el Frente Popular, texto consensuado con las autoridades nacionalistas que fue remitido al papa Pío XI al principio de la Guerra Civil.

\section{Abstract}

Transcription and study of the report accomplished by Alberto Onaindia y Zuloaga to attempt to justify that a catholic party, as the PNV, defended the Popular Front, writting with the help of the nationalistic authorities. It was transmitted to the Pope Pius $\mathrm{XI}$ at the beginning of the Civil War.

\section{El SANGRIENTO VERANO DEL 36}

En julio de 1936, al iniciarse la guerra civil española, el Partido Nacionalista Vasco (PNV) se alineb inequívocamente junto al gobierno del Frente Popular y en contra de los sublevados. Y eso fue sorprendente en muchos círculos católicos europeos y americanos. Pero no era la única sorpresa que se produjo en aquellos momentos: en aquel verano del 36 los españoles veían extrañados que lo que parecia otro pronunciamiento militar, un hecho repetido y ya clásico en la política española del siglo anterior, se transformaba en una cruenta guerra 
civil que prometía durar largo tiempo entre dos Españas que se enfrentaban rencorosa y apasionadamente. Una tercera sorpresa fue que, entre las lógicas represiones iniciales que se dieron en los dos bandos combatientes, apareciese un extraño (y entonces ya arcaico) componente religioso: en la zona gubernamental, a pesar de la libertad de cultos proclamada en la Constitución de 1931, se desató una persecución religiosa contra la Iglesia católica, sus sacerdotes y militantes seglares, y fue tan feroz y con tanto ensañamiento o sadismo que no se conoce otra igual en la historia moderna desde la matanza de los hugonotes en la Francia de 1572.

Estos hechos trajeron consigo que en todo el mundo occidental se viese con enorme curiosidad e interés la lucha que desangraba a los españoles, los cuales dirimían sus diferencias en trincheras y campos de batalla en vez de hacerlo en el hemiciclo parlamentario de una nación en paz y con orden social. $Y$ así, no sólo Hemingway y Malraux, sino muchos intelectuales, escritores y periodistas se interesaron por la guerra, por los españoles, y por el significado de aquella contienda a la que ya entonces se denominó «La última guerra romántica del siglo XX».

La intransigencia y la falta de un deseo de convivencia eran justamente el problema y la espoleta del conflicto: las primeras páginas del libro de Gibson ${ }^{1}$ impresionan por su crudeza a los estudiosos actuales de aquellos hechos. En 1936 el gobierno se vio desbordado por los acontecimientos... y por las organizaciones y milicias «populares» ${ }^{2}$. En uno y otro bando, un paroxismo bélico parecia haberse apoderado de los espanioles, de sus líderes e ideólogos; sin embargo, el bando republicano quedó definido desde los primeros momentos por dos hechos: por un lado, la defensa de la legalidad institucional; por otro, la feroz y cruenta persecución contra la Iglesia católica y sus sacerdotes. Todo ello marcó la guerra española con una extraña perspectiva, como fue la aparición de un «espíritu de cruzada» que la hizo «romántica» a los ojos del mundo:

- Es bien sabido que, en el bando nacional, la Iglesia y las gentes vivieron la guerra civil como una cruzada contra el marxismo y el materialismo ateo, que producía centenares de mártires de la fe por su «odio a la religión». Así lo expuso el Cardenal Gomá: «Es el amor al Dios de nuestros padres el que ha llevado a España a alzarse en armas. En un lado, los campos se

\footnotetext{
t Ian GiBson, La noche en que mataron a Calva Sotelo, Barcelona, Planeta, 1975.

2 El término «popular» tiene desde 1789 unas connotaciones democráticas, por hacer referencia a la soberanía del pueblo. Pero evidentemente ese término se utilizó con otro contenido diferente en la España de 1936, sobre todo cuando se usó para designar algunos tribunales y milicias de partidos y sindicatos socialistas, comunistas y anarquistas. Diez afios después, y con el mismo contenido, se volvería a utilizar en la Europa Oriental para designar las «democracias» creadas por Stalin.
}

Actas del I Congreso de Historia de la Iglesia y el Mundo Hispánico

Hispania Sacra, 52 (2000) 
han convertido en templos; en el otro, miles de sacerdotes asesinados, las iglesias destruidas, una furia satánica $[\ldots .].\rangle^{3}$. Así había quedado también formulado en la famosa "Carta colectiva del Episcopado español» a los obispos de todo el mundo, aparecida el 1 de julio de 1937, y cuya autoría se atribuye a Gomá $a^{4}$.

- Pero también en el bando republicano se vivió la guerra como una cruzada contra el fascismo: Dimitrov y la Komintern venían anunciando durante años que el fascismo amenazaba a Europa y era preciso frenarlo a toda costa. Ese espíritu era el que había llevado a la formación del «Frente Popularo en la Espafia de febrero de 1936, y es el que explica por qué a partir del mes de julio varios grupos político-sociales se plantearon si primero se debía ganar la guerra y luego hacer la revolución, o si lo prioritario era hacer la revolución y luego dedicarse a ganar la guerra. Por eso, muchos hombres en todo el mundo recogieron la llamada a una cruzada antifascista en España, y acudieron a los centros de reclutamiento abiertos por el partido comunista de cada país para alistarse como voluntarios en - las Brigadas Internacionales ${ }^{6}$, de cuya moral de combate y «espíritu de

${ }^{3}$ F. G. Bruguera, Histoire contemporaine d'Espagne, 1789-1950, Paris, Ophrys, 1953, p. 426. Véase J. ANDRÉs GALLEGO, "El nombre de "Cruzada" y la guerra de España», en Aportes, n. ${ }^{\circ} 8,1988$, p. 65; y recuérdese también la obra (aún vigente) de V. PALACIO ATARD, Cuadernos bibllográficos de la guerra de España (1936-1939), editados en varios volúmenes en Madrid, Universidad Complutense, de 1966 a 1970.

${ }^{4}$ La «Carta» supuso a la zona nacional un gran apoyo, también internacional. Hug THOMAs la cree sugerida por Franco (La guerra civil española, París, Ruedo Ibérico, 1967, p. 530), pero es más lógico que los obispos la firmasen impelidos por la persecución desatada en la zona republicana contra los sacerdotes y militantes católicos. Parece que Gomá fue ayudado y asistido en la redacción por Pla $i$ Deniel (obispo de Salamanca) y por Eijo y Garay (obispo de Madrid-Alcala). Sobre la figura del cardenal Gomá hay dos interesantes estudios: A. GRanados, El Cardenal Gomá, Primado de España, Espasa-Calpe, Madrid, 1969; y M. L. RoDríguez Aisa, El Cardenal Gomá y la guerra de España Aspectos de la gestión pública del primado, 1936-1939, CSIC, Madrid, 1981.

${ }_{5}^{5}$ Georgi Dimirov era líder del partido comunista de Bulgaria, y fue elegido Secretario General de la Komintern en su VII Congreso. Muchos de sus discursos de esta época propugnan una cruzada antifascista, y son más fáciles de consultar en italiano que en búlgaro, en su obra Dal fronte antifascista alla democrazia popolare, Rinascita, Roma, 1950, especialmente las pp. 58-59, 68-69 y 75-76. Sobre el reflejo de este espíritu en la guerra de Espafia, J. ANDRÉs GaLLEGo, «Las razones del odio y del amon, en A. MONTENEGRo DUQUE (coord.), Historia de Epaña. La guerra civil (vol. 13,1), Gredos, Madrid, 1989, pp. 39 y ss.

${ }^{6}$ Un testigo me contó que en 1936 era adolescente y estudiaba francés, y se acercó a las trincheras de los brigadistas para practicar con ellos el idioma que estudiaba. Uno le dijo que alli eran todos comunistas, y el joven le preguntó si había también algún miembro de ơtro partido francés. La respuesta fue muy significativa: «Un demócrata? Esos son como conejos; pero busca por ahí: alguno habrá." Sin embargo es conocido que el Congreso de los Diputados (28 noviembre 1995) concedió a los supervivientes de las Brigadas Internacionales la ciudadania espantola y les festejó como edefensores de la democracia y la libertady. La condena de ơros sectores, muy clara y rotundamente expuesta, apa-

Actas del 1 Congreso de Historia de la Iglesia y el Mundo Hispánico Hispania Sacra, 52 (2000) 
cruzada antifascista» se ocupaban los Comisarios políticos envidos por la Komintern.

El «espíritu de cruzada» que se respiraba en ambos bandos, y el radicalismo de sus planteamientos, se simultaneaban con extraños conflictos internos en cada uno de ellos: entre los republicanos, unos defendían la legitimidad democrática mientras que otros querían realizar una revolución social y política de carácter radical o marxista; a su vez, entre los sublevados había quienes defendían su existencia como opción política democrática, otros que abominaban de la democracia, y otros que amalgamaban sus ideas políticas con sus creencias religiosas, aunque todos ellos trataban de salvar su vida fisica ${ }^{7}$. Precisamente el radicalismo e intransigencia de actitudes produjo que, en las mentalidades sociales de aquellos españoles, lo político fuera pasando paulatinamente a un segundo lugar y en prioridades fuese desplazado por lo social (en un bando) o lo religioso (en el otro bando).

\section{INICIO DE LA PERSECUCIÓN RELIGIOSA EN MADRID}

En Madrid las cosas se sufrían en toda su crudeza. Al contrario que en el País Vasco, en la capital no había un gobierno de católicos que intentase defender a los clérigos frente a la persecución de turbas exaltadas o de milicias sindicales o de partido. A pesar de ello, cuando se produjo el alzamiento del ejército de África, Casares Quiroga (presidente del gobierno) avisó a D. Leopoldo Eijo y Garay (obispo de Madrid-Alcalá) «no como obispo, sino como paisano» para que abandonase Madrid, puesto que en las horas siguientes no podía responder de su vida. El mismo 18 de julio por la tarde, cuando en Madrid corrian rumores de que se pensaba armar al pueblo para sofocar la sublevación militar, Mons. Eijo emprendió viaje por la carretera de La Coruña hacia su Vigo natal; al llegar a Torrelodones, el párroco y el alcalde le aconsejaron que per-

reció en R. DE LA CTERVA, Brigadas internacionales. Madridejos, Fénix, 1997; en Razón Española (n. 81 , p. 61, y n. ${ }^{\circ} 82$, p. 204) y en el Boletín de la Fundación Francisco Franco. La prensa silenció o descalificó estas opiniones (a modo de ejemplo, la revista Tiempo, n. $.^{\circ} 758-11$ nov. 1996-,p. 117), o dio su apoyo y homenaje a los brigadistas, presentándoles como demócratas (ibid., p. 130).

7 Ya GiL-Robles había declarado en las Cortes: «La mitad de la nación no se resigna implacablemente a morir” (Discursos parlamentarios, Taurus, Madrid, 1971, p. 561). Esa media Espafia, como huego se vería en la guerra, sabía que la querian eliminar físicamente sólo por sus ideas políticas o religiosas, y se aprestó a defenderse... y en otros casos a prepararse a morir; para entender este último aspecto, parece muy conveniente recordar la letra del himno de las Juventudes Masculinas de ACCIÓN CATÓLICA, estrenado en un Congreso que tuvieron en 1932: «[...] Ser apóstol, o márfir acaso, / mis banderas me enseitan a ser $[\ldots], n$

Actas del I Congreso de Historia de la Iglesia y el Mundo Hispánico Hispania Sacra, 52 (2000) 
noctara allí, pues respondían de su seguridad. Al día siguiente continuó por Galapagar, para evitar el control de milicianos establecido a la entrada de Villalba, y tras varios episodios más consiguió llegar a Vigo, donde permaneció a salvo y en seguro la mayor parte de la guerra.

Como había supuesto acertadamente Casares Quiroga, las turbas exaltadas y las milicias asaltaron el palacio episcopal, acribillando a balazos y cuchilladas un retrato de Mons. Eijo colgado en su sala de visitas; al día siguiente, los diarios madrilefios resaltaban con sorna que en la curia había aparecido una suctlenta suma de dinero, así como valores y joyas ${ }^{8}$. Mientras tanto, el clero diocesano de Madrid, compuesto en 1936 por 1.118 sacerdotes, así como los religiosos establecidos en la capital, iniciaban una etapa traumática, que comenzaba con el miedo a la venganza de las turbas -exaltadas tras lo ocurrido en el Cuartel de la Montaña-, y culminaría con diversas formas de dispersión. En estas circunstancias, es comprensible que la mayoría del clero madrileño procurase encontrar un medio de salvar su vida. 'No hay documentación que muestre con certeza lo que entonces hizo cada uno, aunque sí existen documentos y relatos de los protagonistas o de algunos testigos que nos permiten reconstruir lo que sucedió en aquellos días de horror y persecución.

En líneas generales, puede decirse que los clérigos de la capital, atemorizados por lo que ocurría en las calles durante los primeros días del alzamiento militar, evitaron mostrarse en público. Los más prudentes se escondieron en casas de familiares o amigos; varios, en su desconocimiento ingenuo o confiado de la situación, tuvieron que ser arrastrados casi a la fuerza por sus padres o hermanos. Algunos pidieron asilo en embajadas o lugares con extraterritorialidad diplomática. Otros, imitando a su Obispo, dejaron la ciudad y por diversos medios se dirigieron a las líneas nacionales, tomando parte en la guerra encuadrados como capellanes militares. Los que no pudieron huir se camuflaron en trabajos y puestos diferentes: hubo curas o seminaristas que fueron reclutados en el Ejército republicano (el actual obispo emérito de Segovia, Antonio Palenzuela, por ejemplo), y algunos -por saber leer y escribir correctamente- actuaron como secretarios de pueblos o de regimientos militares, e incluso hubo algunos que tuvieron que alistarse como milicianos. Otros hallaron medios ingeniosos para seguir libres y ejercer clandestinamente (con riesgo de su vida) sus funciones sacerdotales. Finalmente, otros muchos fueron apresados.

\footnotetext{
8 Véase el interesante artículo del que fuera Deán de la catedral de Madrid, Salvador MUNoz IGLESIAS, "Cuarenta afios para un obispo: D. Leopoldo Eijo Garay", en Cuadernos de Historia y Arte. Centenario de la Diócesis, $\mathbf{n} .{ }^{\circ} 2,1985, \mathrm{p} .80$. También merece recordarse la obra de $\mathrm{R}$. ABELLA, La vida cotidiana durante la guerra civil. La España republicana, Planeta, Barcelona, 1976 (20 ed.), p. 24.
} 
Entre estos últimos, la mayor parte fueron capturados y ejecutados de inmediato"; bastantes fueron llevados a cárceles o a "checas» (la de la calle de Fomento adquirió entonces una triste fama), donde sólo unos pocos permanecieron toda la guerra, mientras que la casi totalidad fueron «paseados» ${ }^{10}$. Pero también hubo sacerdotes que, o bien por voluntad propia o por sugerencias externas, recibieron propuestas para formar un grupo de clérigos «adictos» a la República, y la sirvieron como régimen legal: son conocidos, en este sentido, los casos de los sacerdotes republicanos Leocadio Lobo y García Morales, así como el papel que en Toledo le tocó jugar al canónigo lectoral de Madrid, Camarasa, a quien los republicanos sacaron de la prisión para que su probada oratoria inclinara a Moscardó a rendir el Alcázar asediado.

Respecto a los curas de los pueblos madrileños, las situaciones abarcaron desde el más crudo sadismo (hubo uno a quien mataron a hachazos, y otro al que descuartizaron) hasta situaciones próximas a la comicidad (en algún lugar los aldeanos corrían tras el cura, campo a través, por los trigales). En muchos casos, los campesinos de un pueblo llamaban a los de otro para que éstos fusilaran al cura local, dado que a ellos les daba una cierta vergüenza; en otros avisa-

\footnotetext{
${ }^{9}$ Resulta espeluznante la lectura de los testimonios conservados en el Archivo del Arzobispado de Madrid, y más concretamente las referidas a las circunstancias de aquellas muertes. Por ejemplo, de los Dominicos de Atocha se escribe que el 18 de julio de 1936 ufueron arrastrados por las calles, y el subprior muerto a hachazos»; un cura de Chamberi fue «descuartizado», otro «apareció con 40 tiros», a otro «después de muerto le sacaron los ojos y apurialaron», a uno le mataron «a palos», a dos «los prendieron con gasolina y los quemaron aún vivos», y el cura de la parroquia de Covadonga «fue llevado atados los brazos a unos palos en cruz y muerto a estocadas». El propio Obispo, en las honras fúmebres, por sus sacerdotes asesinados, recordaba que el cura de Santos de la Humosa, al ser detenido y llevado al Ayuntamiento de Corpa, «fue gravemente herido; atado luego a un coche automóvil, fue arrastrado por las calles, y tan ferozmente que perdió un brazo y una pierna [...]”. A] margen del sadismo popular, a otros se infligieron escarnios y malos tratos: un informante, entre otras cosas, recordaba haber presenciado que el Obispo de Cuenca, antes de ser asesinado, fue «vejado y maltratado»; también hubo quien murió por el miedo (de uno se dice que «murió en un "paseo": angina de pecho") y quien caý́ santa o heroicamente: uno hasta «arengó a sus asesinos», y el cura de El Pardo, Cipriano Martinez Gil, fue «fusilado de rodillas y en cruz voluntariamente». Véase el legajo «CARPETA "F", Serie IV", del que se hablará después.

10 A. Montero Moreno, Historia de la persecución religiosa en España, 1936-1939, BAC, Madrid, 1961. Tradicionalmente y desde su aparición, esta tesis doctoral del que luego sería el obispo de Badajoz ha sido considerada el mejor exponente de la persecución religiosa ocurrida en España, aunque su tratamiento sea un tanto matizable; por eso ha suftido algunas criticas por parte de historiadores que pretenden ser profesionales, aunque su optica resulte sospechosa de parcialidad (y en algún caso equivocada) por sus posicionamientos y por sus circunstancias personales o subjetivas. Incluso $\mathrm{H}$. THOMAS sefiala en su obra (ob. cit., p. 198) que «los sindicatos y los partidos políticos de la República establecieron grupos especiales de investigación política, que se enorgullecían de llamarse a sí mismos, a la manera rusa, con el nombre de checas. Sólo en Madrid existieron 227; todo ello se encuentra bien documentado en la Causa General, p. 82.
}

Actas del I Congreso de Historia de la Iglesia y el Mundo Hispánico Hispania Sacra, 52 (2000) 
ban al cura para que huyera, $y$, tras su marcha, se asaltaba y saqueaba la casa rectoral, y se quemaba la iglesia parroquial dentro de la más pura tradición revolucionaria española. En general, los pueblos pequeños solían respetar la vida del párroco, mientras que en los grandes le mataban: normalmente, estos jóvenes sacerdotes rurales, por su inexperiencia y alto idealismo, no huyeron rápidamente y fueron casi todos asesinados.

Cuando a las pocas semanas se estabilizó la situación, y todo el mundo era consciente de que España se encontraba en una guerra civil de incierta duración, el obispo Eijo Garay y los dirigentes diocesanos trataron de relacionarse entre ellos y, una vez logrado, se aprestaron a organizar sus ayudas y socorros para los sacerdotes que habían quedado en Madrid, unos en las cárceles (especialmente en la Cárcel Modelo, de la que el recuerdo de las «sacas» o asesinatos en ella perpetrados llevaría a las autoridades franquistas a demolerla hasta los cimientos), y otros camuflados en diversas ocupaciones, pero ejerciendo sus funciones religiosas. Poco a poco, los dirigentes eclesiásticos de Madrid fueron recibiendo noticias y estableciendo medios de información (incluso a través del republicano Servicio de Información Español) o de comunicación con sus sacerdotes, tanto con los que habían conseguido salir de Madrid y se ofrecían a su obispo o con los que estaban a salvo en embajadas y edificios consulares, como con los que seguían ejerciendo clandestinamente en el Madrid republicano.

\section{EL «INFORME ONAINDÍA»}

Pronto conoció el mundo entero la feroz persecución religiosa que se había desatado en Espania. Y así, en septiembre de 1936 tuvo lugar la primera reacción del Papa Pío XI ante la guerra de España: en Castelgandolfo, ante 600 refugiados espańoles, habló del «odio verdaderamente satánico contra Dios» de los republicanos. Sus palabras fueron contestadas por García Morales, un sacerdote que había tomado posición en el lado de la República, quien pidió al Papa que denunciara a los rebeldes. Días después, el apologista católico José Bergamín, editor de la revista Cruz y raya, describiría a los generales, moros, carlistas y obispos que luchaban contra la República como envueltos en una «fantástica mascarada de la muerte». Contra esta propaganda, el Obispo de Salamanca, Mons. Pla i Deniel, publicó entonces su carta pastoral Las dos ciudades, de fuerte espíritu ignaciano: en aquellos momentos había que alinearse claramente «con» Dios o «contra» Dios.

Es lógico que el Vaticano, y los católicos y gentes civilizadas de todo el mundo, preocupados ante las noticias recibidas de obispos y sacerdotes españo- 
les, y otras conseguidas por diversos conductos diplomáticos y periodísticos, se preguntasen qué estaba ocurriendo en España con los sacerdotes: las noticias sobre persecución y asesinatos de políticos y clérigos habían despertado en el mundo el mismo interés y desconcierto que veinte años antes habían suscitados los sucesos en la Rusia revolucionaria de 1917. Para mejorar su imagen internacional y negar la existencia de persecución religiosa en la España republicana, los gobiernos de Martínez Barrio (julio-septiembre 1936), Largo Caballero (sept.1936-mayo 1937) y Negrín (mayo 1937-abril 1938) tomaron varias medidas. Una de ellas fue encargar al sacerdote madrilefio Leocadio Lobo ${ }^{11}$, adicto a la República, que hiciese oficiosamente de embajador volante en distintos puntos de Europa (Paris, Bruselas, Amberes, Londres) y que expusiera en la pren$\mathrm{sa}^{12}$ que el cristianismo -y la política vaticana- eran incompatibles con los regímenes totalitarios, y por eso tendrían que mostrarse opuestos al gobierno de Burgos y a sus aliados alemanes e italianos. Otra medida del gobierno republicano fue sugerir la creación y visita a España de varias Delegaciones y Comisiones (inglesas y francesas, especialmente), para que a lo largo de 1937 viesen sobre el terreno la inexistencia de una persecución religiosa; los informes de estas Comisiones fueron favorables al gobierno porque describían la práctica religiosa y a la ausencia de persecución... en el País Vasco. Pero la medida más decisiva fue la disposición del ministro Irujo, recogida en la republicana Gaceta de Madrid (21 junio 1937), de liberar a los presos no sometidos a procedimiento judicial, lo cual supuso la excarcelación de muchos sacerdotes.

Con todo, Roma no se dejó engañar: al margen de la propaganda y los informes de las Delegaciones, el Vaticano poseía la famosa Carta colectiva, los informes que habían enviado los obispos españoles, y el testimonio de numerosos huidos de la zona republicana, que relataban acciones y asesinatos escalofriantes de los que habían sido testigos directos. Por eso la Secretaría de Estado vaticana envió en abril de 1938 a Mons. Hildebrando Antoniutti como Delegado Apostólico ante el gobierno de Burgos, no ante el de Madrid, por ser aquel gobierno el que protegía a la Iglesia, a sus sacerdotes y a la religión, y porque en su territorio hallaban refugio seguro todos los clérigos que huían de las persecuciones y las cárceles del gobiemo republicano.

\footnotetext{
11 Leocadio Lobo Canónigo era un sacerdote que, en 1936, ejercia de coadjutor en la madrileña parroquia de San Ginés. Por simpatizar con la causa republicana, actuó como propagandista religioso de la misma y, tras el fracaso ante el Vaticano de estas propagandas y las gestiones del ministro upeneuvista» Irujo, intentó crear una «lglesia nacional» obediente a la República. Sobre Leocadio Lobo, véase MUÑoz IGLESIAS, ob. cit., y ABELLA, ob. cit., pp. 57 y 60.

12 Los artículos más interesantes de este sacerdote, tachado por sus compañeros de la diócesis de Madrid como traidor y renegado, aparecieron en EL LIBERAL de Madrid a lo largo del verano de 1937, si bien los más significativos son los de los días 15 y 24 de agosto.
}

Actas del I Congreso de Historia de la Iglesia y el Mundo Hispánico Hispania Sacra, $52(2000)$ 
Con el mismo objetivo propagandístico del gobierno republicano, también el PNV había buscado lavar su imagen pública, y explicar su postura al Vaticano: en ese contexto internacional es donde debe inscribirse el «Informe Onaindía», documento llamado así por su autor, quien lo redactó por encargo del PNV. Alberto Onaindía y Zuluaga era en 1935 canónigo por oposición de la Catedral de Valladolid, en cuya diócesis estaba incardinado, teniendo como superior u Ordinario al arzobispo de la sede metropolitana de Valladolid, D. Remigio Gandásegui. Es sabido que el inicio de la sublevación militar (o Alzamiento Nacional ) sorprendió al arzobispo en la clínica del Dr. D. Benigno Oreja, de San Sebastián: fue apresado por milicianos anarquistas y llevado a Bilbao. Sin embargo, por estar en el País Vasco y ser las autoridades del PNV las que controlaban el poder, pudo el arzobispo ponerse en contacto con su canónigo, D. Alberto Onaindia, pues sabía que contaba con amistades importantes dentro del PNV. Por mediación de Onaindía su caso llegó a conocimiento del PNV, el cual procuró ante los anarquistas su entrega con el pretexto de que debía ser trasladado urgentemente a San Sébastián (ya entonces en poder de los nacionales) por cuestiones de salud; tras conseguirlo, las autoridades vascas lo entregaron a los militares nacionales en el mismo frente de guerra.

A raiz de su intervención en la liberación de su Arzobispo, Onaindía recibió de José Antonio Aguirre el encargo ${ }^{13}$ de explicar al Papa Pío XI (1922-1939) por qué un partido católico y confesional como el PNV se había posicionado en la guerra civil española al lado de una República «atea» que perseguía a la Iglesia y sus sacerdotes, y en contra de un movimiento militar que defendía los valores cristianos. $E 1$ «Informe Onaindía» tiene 19 páginas ${ }^{14}$ mecanografiadas a un solo espacio, que se complementan con otro escrito suyo de aquellas mismas fechas y dos apéndices más. Fue escrito por el canónigo vasco a partir del 26 de agosto de 1936, en colaboración con José Antonio Aguirre (primer lehendakari), Juan Ajuriaguerra y Julio Jáuregui, y presentado por el mismo Onaindía, como comisionado por el PNV, en la Secretaría de Estado del Vaticano el 23 de

${ }^{13}$ A. DE ONADNDIA Y ZuLUAGA, Hombre de paz en la guerra. Capitulos de mi vida, Editorial vasca Ekin, Buenos Aires, 1973 (2 vols.).

${ }_{14}$ El «Informe Onaindfa» se encuentra en el Servicio Histórico Militar, en el legajo 58, carpeta 5, documento 2 (pp. 83-101), armario 46. El documento se créa perdido tras la rendición de las fuerzas vascas en Santoña, pero fue encontrado por el Prof. José GutTÉrREz ÁLVAREZ e incluido como apéndice en su Tesis doctoral inédita titulada Aspectos pollticos y religiosos del nacionalismo vasco, UCM, Madrid, 1970. El rigor investigador de este profesor fue tal que liegó a entrevistar para su Tesis al mismo general Franco, como reflejó su primo Francisco Franco SALGADO-ARaújo en su conocido libro Mi vida jonto a Franco, Madrid, Planeta, 1977. En 1987 se suscitó una curiosa polémica al publicar Fernando de MEER, profesor de la Universidad de Navarra, el referido documento como un hallazgo; tras unas aclaraciones publicadas en la prensa, este profesor rectificó caballerosamente su error en el n. 805 (4 mayo 1987), p. 53, de la revista CAMBIO 16. 
octubre. Sus gestiones en la curia y dicasterios vaticanos fueron de tal calidad que llegó a entrevistarse con el Papa tiempo después, cuando el derrotado gobierno vasco se encontraba en el exilio: "Yo me negué a besarle el anillo -señala en sus memorias-y le contesté al Santo Padre que yo también tenía mi dignidad.»

Señalaba Onaindía en su informe al Vaticano que los dirigentes del PNV le hicieron «descargo de su conciencia de católicos y creyentes en el grave problema moral» planteado en sus conciencias por la decisión y compromiso del PNV de alinearse con el Frente Popular. Y explicaba que «el PNV es por su fe religiosa católico, apostólico y romano», pero que en su aspecto civil es "patriota vasco, reconoce como Patria al País Vasco, Euzkadi, y tiende al reconocimiento de sus derechos tradicionales». Sobre el posicionamiento del partido en la gueIra afirmaba que el PNV «coincide de hecho en combatir con los del FRENTE POPULAR al conjunto Cívico-Militar levantado en armas contra el Gobierno de Madrid. Este Frente Popular ha cometido crímenes y sacrilegios en personas y cosas en toda Espafia). Explicaba Onaindía esa actitud del PNV senfalando que ese partido no se consideraba como una mera organización política, sino como exponente y reflejo de todo un pueblo, contando con un sindicato obrero muy fuerte, y con un carácter marcadamente proletario y de clase media: en esto se separaba de las «derechas» españolas, a las que acusaba de oponerse a todo avance social así como al programa patriótico vasco, al que siempre habian combatido.

En esa misma línea exculpatoria del PNV se había manifestado también, ya liberado de los anarquistas y entregado a los nacionales, un agradecido y emocionado Mons. Gandásegui, que acababa de ser salvado de una muerte cierta: «La postura del PNV ha sido la de la Providencia, que ha salvado al pueblo vasco de una hecatombe de horrores y crímenes cometidos por los marxistas» ${ }^{15}$. El arzobispo recién liberado no podía imaginar entonces que similares crímenes se iban a producir también en el País Vasco, en enero y en marzo de 1937.

En 1987, a punto de cumplir los 85 años y desde su domicilio en la localidad francesa de San Juan de Luz (a la que huyó al rendirse las tropas vascas), el canónigo Onaindía se justificaba medio siglo después: «No es que apoyáramos a la República y a los socialistas. Nuestra motivación principal fue defender la libertad del País Vasco, que se veía entonces amenazada) ${ }^{16}$. Respecto al juicio sobre su intervención personal (y la del PNV) en aquellos tiempos de persecución religiosa, Onaindía ya dejó escrito en su «Informe» que el PNV se habia

is «Nuevo documento y testimonios. Por qué el PNV no apoyó a Franco en la guerra», en CAMBIO-16, n. ${ }^{\circ} 805$ (4-V-1987), p. 53.

16 Véanse sus declaraciones en el artículo citado en la nota anterior, pp. 50 y ss.

Actas del I Congreso de Historia de la Iglesia y el Mundo Hispánico Hispania Sacra, 52 (2000) 
esforzado el preservar el orden público en Euskadi «frente a los crímenes y los sacrilegios cometidos por los marxistas en toda Españan. No obstante, a la hora de valorar e interpretar aquellos hechos, y los varios escritos enviados por Onaindía al Vaticano, es necesario tener muy presentes las palabras del exlehendakari Jesús María de Leizaola, quien también cincuenta años después de aquellos sucesos recordaba que la postura del canónigo vasco no siempre coincidía con la de los políticos vascos ni con la del PNV: «Sé que Alberto Onaindía ha sido un hombre valioso para José Antonio Aguirre, pero también tuvieron sus discrepancias en el terreno político» ${ }^{17}$.

A pesar de la explicación que el «Informe Onaindía» proporcionó a la Secretaría de Estado, el Vaticano buscó otros medios de indagación seguros y contrastados. Con toda probabilidad, la primera información procedente del bando republicano debió ser el llamado "Informe Inujo» (7 enero 1937), habitualmente citado para conocer los dafios sufridos por la Iglesia en los primeros meses de la guerra. Manuel de Irujo, afiliado al PNV, fue Ministro sin Cartera desde el 25 de septiembre de 1936 hasta el 17 de mayo de 1937 en el gobieno republicano de Largo Caballero; al salir los anarquistas del gabinete, quedó como Ministro de Justicia en el del Dr. Negrin, en sustitución del anarquista García Oliver. Como católico, se esforzó en aminorar la persecución religiosa, salvar el mayor número posible de sacerdotes y religiosos en las cárceles y checas, y restablecer las relaciones diplomáticas con la Santa Sede ${ }^{18}$, rotas por la cuestión religiosa; no es, pues, de extrañar que en sus primeros contactos con el Vaticano ofreciese el mencionado informe.

Para el Vaticano, la mejor fuente resultó ser la «Encuesta Antoniutti». En la primavera de 1938, Mons. Hildebrando Antoniutti, entonces Delegado Apostólico de Su Santidad ante el gobierno de Burgos y afios después (tras el Concordato de 1953) Nuncio de Su Santidad en España, remitió una encuesta a todas las diócesis de la España «nacional»; enviarla a la España republicana no sólo era impensable, sino imposible. Publicada en la mayoría de los Boletines eclesiásticos, tenía cinco apartados con numerosas preguntas en cada uno de ellos: cuestiones generales, personas, cosas sagradas, otros bienes de la Iglesia, y culto. Esta encuesta produjo una mayor información, y de más fiabilidad y contraste (se encargaba la curia en cada diócesis) que el informe del ministro Irujo

17 Ibidem.

18 V. PALAClo ATARD, «Intentos del gobierno republicano de restablecer relaciones diplomáticas con la Santa Sede durante la guerra civil», en Cinco historias de la República y la guerra, Editora Nacional, Madrid, 1973. También son de gran interés A. MARQUINA BARRIO, La diplomacia vaticanay la España de Franco, 1936-1945, CSIC, Madrid, 1983. R. SALAs LARRAZABaL, "Situación de la Iglesia en la España republicana durante la guerra civil», en VI Semana de Historia eclesiástica de la España Contemporánea, CUMO Cristina, S. Lorenzo del Escorial, 1983. 
y que los datos suministrados por el republicano Servicio de Información Español.

\section{El CLERO EN EL MADRID REPUBLICANO}

En octubre de 1936, y tras la toma de Toledo y el nombramiento de Franco como Generalísimo y Jefe del Estado Español, las tropas del general Varela habían conquistado el SO de la provincia madrileña (San Martín de Valdeiglesias, El Tiemblo), iniciando las famosas cuatro columnas su avance hacia la capital: el 4 de noviembre llegaban a Getafe, y el 5 a Leganés y Alcorcón. Parecía que Madrid iba a caer: Franco anunció que la liberación de la capital era inminente, y pidió a los madrileños que permanecieran en sus casas. Simultáneamente, en Avila se formaba la administración municipal que había de regir la ciudad en cuanto fuera tomada por las tropas nacionales, y se iban acumulando camiones con alimentos para la población de Madrid ${ }^{19}$.

Sin embargo, la ciudad no se tomó entonces por la resistencia que opusieron sus habitantes, quienes recibirían enseguida la ayuda de las Brigadas Internacionales; todos los preparativos y previsiones resultaron, pues, vanos: Madrid conocería en carne propia todo el horror de la guerra. Por ello, Mons. Eijo Garay se aprestó a ayudar al clero que permanecía dentro de la ciudad ejerciendo secretamente su ministerio: la vida religiosa seguía funcionando camuflada en casas particulares, pensiones, hospitales y otros centros, donde periódicamente se celebraba misa. Hasta en las cárceles, y bajo la más estrecha vigilancia, se llegó a mantener el culto ${ }^{20}$. El obispo y la curia madrileña se ocuparon de enviar al clero diocesano que aún permanecia en Madrid algún dinero, bien como «estipendios de misas», bien como auxilios para satisfacer sus necesidades más perentorias; de igual modo, procuraron suministrarles hostias y vino para celebrar misa y

19 Al igual que las autoridades civiles o militares, Mons. Eijo y Garay empezó a trazar planes sobre su diócesis, y nombró Vicario general a Francisco Morán, e instaló la curia diocesana en EJ Álamo (después en Navalcarnero y, finalmente, en Cadalso de los Vidrios). Mientras, en el Madrid republicano, tenía como vicario a Manuel Rubio Cercas, oculto en la embajada de Noruega; al evadirse éste en 1937, quedá como vicario el provisor del Obispado, Heriberto Prieto Rodríguez, refugiado en el Hospital de S. Luis de los Franceses (y por ello con extraterritorialidad); cuando también éste consiguió pasar a Francia en 1938, nombró vicario a José M. García Lahiguera, que gozaba de una situación privilegiada por ser hermano de un diplomático con gran influencia ante Fernando de los Ríos, embajador a la sazón en EE.UU.

${ }^{20}$ Incluso en las cárceles había clandestinamente culto católico. En varias de ellas se llegaron a organizar «tumos de vela ante el Santísimo»: una hostia consagrada se camuflaba en una caja de cerilias que un sacerdote (o un caballero, si no habia sacerdotes) mantenía sobre una rodilla mientras simulaba estar fumando sentado.

Actas del I Congreso de Historia de la Iglesia y el Mundo Hispánico Hispania Sacra, 52 (2000) 
mantener el culto clandestino entre los fieles de la capital: jeste «Socorro sacerdotal ${ }^{21}$ llegó a reunir mensualmente hasta 71.000 pts. de la época!

En el interior de la capital sitiada, mientras tanto, el vicario García Lahiguera ejercía una gran labor, espiritual y humana, con los clérigos madrileños. Cada semana se reunía un día con los sacerdotes, y otro con los seminaristas, en un piso amparado por el pabellón de la embajada de Cuba, en la calle Hermosilla número 12, habitado por religiosas de María Reparadora; en estas reuniones, además, se organizaba la asistencia religiosa de la capital. Quizás por eso el clero madrileño de la capital se mantuvo fiel a sus principios y a su jerarquía: «El índice de perseverancia del clero diocesano fue ejemplarísimo», afirma Muñoz Iglesias: aunque de los 1.118 sacerdotes diocesanos que tenía Madrid en 1936 fueran asesinados 335 (el 30\%), la única deserción conocida fue la de un sacerdote que se casó por lo civil. Lo mismo ocurrió con los seminaristas: de los 214 del curso 1935-36, tras el fusilamiento de 17 de ellos, ingresaron 102 en 1939 (de mayo a octubre), y 195 en el curso.1939-4022.

En este sentido es de destacar el rechazo total de los sacerdotes consultados cuando el ya mencionado Leocadio Lobo Canónigo, antiguo coadjutor de la parroquia de S. Ginés, de acuerdo con el gobierno republicano, prometí la libertad de los sacerdotes encarcelados (después ejecutados) y la apertura de las iglesias al culto a cambio de la firma de un documento de adhesión: eso equivalía a la creación de una «Iglesia popular» adicta a la República -y por ello cismática-, tal como veinte años después haría Mao-Ze-Dong en China ${ }^{23}$. No consiguió ninguna adhesión: uno que firmó por miedo, cuando se dio cuenta de lo que había hecho, se presentó a exigir que se borrara su firma. En 1939, a pesar de las múltiples noticias que recibía, la curia diocesana instalada en Cadalso de los Vidrios tenía muchas incógnitas sobre la suerte de los sacerdotes que en 1936 habian quedado en la capital.

21 Esta ayuda económica la habian iniciado en el mes de octubre las jóvenes de Acción Católica de la parroquia de Sta. Teresa y Sta. Isabel (situada en la glorieta de Iglesia, en pleno barrio de Chamberi), recaudando cuotas fijas y estipendios de misas para casi treinta sacerdotes escondidos de los que ellas tenian conocimiento. Esta red asistencial para clérigos se amplió después, en mayo de 1937, a nivel diocesano bajo la dirección del mencionado provisor Heriberto Prieto, quien encomendó la recaudación y distribur ción de los fondos al secretario de la Junta central de ACCIÓN CATÓLICA, José M. Taboada Lago.

22 MuNoz Iglesias, ob. cit; y Martínez. SANZ, «La "Información” del Obispado de Madrid...» (véase nota 26), p. 593 y 581 .

23 Véase M. DE UNCIT1, «Historia, Teología y Derecho al servicio de la Iglesia en Chinas, en LUMEN, n. ${ }^{\circ}$ 9, 1960, pp. 317-338 y 385-403. Como es sabido, el problema de la «Iglesia patriótica chinas, creada en 1958, es un problema que aún persiste y que impide las normales relaciones de la República Popular China con la Santa Sede, cuyos obispos están aún en las cárceles gubernamentales. Parece que recientemente las autoridades de Pekín han liberado a un obispo, y se hallan en vias de negociación diplomática. 


\section{LA VICARÍA DE REORGANZACIÓN Y SU «INFORMACIÓN»}

Hacia el mediodía del martes 28 de marzo de 1939 empezaron a entrar en Madrid las tropas nacionales, mandadas por el general Espinosa de los Monteros; hermanados con los soldados, muchos sacerdotes diocesanos penetraron también en la capital, junto con sus superiores. Su primer impulso fue dirigirse al Obispado, el viejo caserón de la calle de La Pasa, para reinstalar en él una Curia provisional (como un (cuartel general» eclesiástico): allí fueron a encontrarse y abrazarse con sus compañeros sacerdotes que durante los tres años de guerra habían ejercido en Madrid clandestinamente, así como con los que habían marchado fuera de la diócesis para salvar su vida, y con el clero diocesano que volvía a la ciudad. A la vez, se apresuraron a recuperar los edificios religiosos, organizar el culto, y reiniciar la administración de la Diócesis.

Aquel último martes de marzo fue inolvidable para los sacerdotes que habían permanecido en Madrid ocultos y camuflados, al fundirse en un abrazo con sus superiores y compañeros recién llegados. El reencuentro fue memorable para la Iglesia madrileña, pero también para el Vaticano, ya que el 31 de marzo, a las pocas horas de la caída de los últimos reductos republicanos (Almería, Murcia y Cartagena), el nuevo Papa, Pío XII, envió un telegrama al General. Franco: «Alzando nuestro corazón a Dios, damos sinceras gracias con Su Excelencia por la victoria de la católica Españas ${ }^{24}$. Mientras, en la Curia diocesana se creó una Vicaria de Reorganización, que se aplicó de inmediato a dos tareas urgentes: la primera fue distribuir al clero disponible por todas las parroquias de la capital y de los pueblos de la provincia, y la segunda era recabar información sobre los sacerdotes asesinados: por haber sido ejecutados a causa de su fe eran considerados mártires, y una Iglesia que había vivido la guerra como una Cruzada deseaba poderlos ver en el futuro en la gloria de los altares (beatificados o incluso declarados santos), y en aquel presente proponerlos como ejemplos a imitar. Por eso la Vicaría inició una indagación sobre las circunstancias en las que se había producido el martirio de aquellos sacerdotes.

Con este propósito, la Vicaría de Reorganización insertó en el primer Boletín Oficial del Obispado que aparecía tras la guerra un cuestionario o encuesta que los párrocos de todo Madrid debían rellenar y enviar a la Vicaría antes del 31 de julio, titulado Información acerca de los hechos ocurridos durante la revolución. Ésta era en realidad la llamada Encuesta Antoniutti, mencionada en el epí-

24 Testimonio de Alberto Onaindia. Véase THOMAs, ob. cit., p. 710, nota 2. Se trataba de Pío XII, elegido Papa el 2 de ese mismo mes de marzo de 1939, y coronado el día 12 . También en Roma, y sef́ialando un atlas abierto en el mapa đe Espafia, Mussolini comentó a Ciano: «Ha estado abierto por ahí durante casi tres años, y ya es bastante. Pero ya sé seguro que tengo que abrilo por otra página.n En efecto, una semana después iniciaba la invasión de Albania.

Actas del I Congreso de Historia de la Iglesia y el Mundo Hispánico

Hispania Sacra, 52 (2000) 
grafe n. 3 : entonces ya se podía llevar a cabo en un Madrid «liberado de la revolución marxista), y constaba de los mismos cinco apartados que aparecen en el cuestionario de la «Información» del Obispado de Madrid-Alcalá. En su preámbulo, la «Información» ponía gran énfasis en la urgencia de «confeccionar una completa y bien estudiada relación de los acontecimientos relacionados con la vida de la Iglesia durante el período revolucionarion. El hecho de encarecer a los párrocos el interés o transcendencia de las respuestas «por tratarse de asunto importantísimo para la historia de la Diócesis, indispensable para su buena organización", prueba que la intención a objeto de la «Información» era la de iniciar un proceso canónico de beatificación: de ahí las medidas cautelares de veracidad, pruebas, testigos fidedignos, etc. que recomendaba.

Al margen de los resultados ${ }^{25}$ de la «Información», que ya han sido tratados en otro trabajo ${ }^{26}$, en las noticias y testimonios recogidos en fuentes que ofrecian solvencia, las estadísticas de los sacerdotes martirizados por su fe, y otras cuestiones similares y conectadas con éstas, se trasluce una actitud y un objetivo: dar cuenta precisa y exacta de lo ocurrido en Madrid. Nada tiene de extrafio que, en los críticos cinco meses que van desde abril (fin de la guerra española) a septiembre de 1939 (comienzo de la II Guerra mundial), el Vaticano pidiera otras informaciones sobre lo acaecido a los sacerdotes en el resto de Espafía. Algunos sacerdotes de la diócesis madrileña se encontraban fuera de la capital cuando estalló la guerra civil, y podían dar un testimonio veraz, preciso y de primera mano sobre lo que pasó en otros lugares.

Por eso, un testimonio que ofreciera certeza moral y que proporcionase una información veraz de un testigo directo de lo ocurrido en el País Vasco desde el

${ }^{25}$ El cuestionario estaba dividido en cinco secciones: cuestiones generales, personas, cosas sagradas, otros bienes de la iglesia, y culto. Las preguntas del cuadernillo de la (Información" eran muchas, y necesitaban una exacta y pormenorizada respuesta a cada uno de sus aspectos: su recopilación debió proporcionar a quienes la manejaron un conocimiento muy minucioso y exacto de lo ocurrido en Madrid y su provincia. Dado que la situación del momento favorecía la disciplina y la obediencia a los superiores, y por la índole misma del cuestionario, las preguntas fueron contestadas rápidamente y remitido el cuademillo al Obispado; a pesar de ello, algunas contestaciones se retrasaron algo más, y otras no fueron siquiera contestadas. En el Obispado se recibieron 22 respuestas de parroquias de la capital y 160 de pueblos, lo que arroja una cifra inicial de 182 cuadernillos de informes parroquiales; a ellos habría que añadir otros 34 , procedentes de casas religiosas de ambos sexos, lo que supone un total de 216 cuadernillos. Sin embargo, quedaron 50 parroquias rurales sin contestar.

${ }^{26}$ Ese trabajo, mencionado en la nota 22, se trata del artículo de José-Luis MARTíNEZ SANZ, «La "Información" del Obispado de Madrid sobre su clero diocesano durante la guerra civil», en Homenaje a los Profesores José M. "Jover Zamora y Vicente Palacio Atard, Universidad Complutense, Madrid, 1990, tomo II, pp. 569-599. No obstante, el libro de Mons. MonTero Moreno citado en la nota 10 es, con mucho, el más autorizado y clásico entre las diversas obras que tratan de la persecución religiosa en Espaffa. Por lo que a la diócesis de Madrid, se refiere, no debe olvidarse el también citado artículo de Muñoz Iolesias. 
inicio de la guerra hasta la desaparición del gobierno del PNV sería de gran interés a los obispos españoles y al Vaticano, puesto que permitiría valorar lo que había dicho Onaindía sobre los deseos y objetivos del gobierno del PNV, y contrastar lo que decía el canónigo con lo que allí ocurrió de hecho. Por otro lado, además del tono proclive al nuevo régimen español de la casi totalidad de obispos y de muchos sacerdotes, postura lógica en un colectivo que ha salvado la vida gracias a ese régimen, había algunas voces discordantes entre los miembros de la alta jerarquía eclesiástica espaftola: así Vidal y Barraquer, Múgica ${ }^{27}$, etc. Y convenía clarificar la situación, para lo que se necesitaba todo tipo de informaciones sobre hechos y conductas durante la guerra civil que acababa de concluir.

\section{El «CONTRAINFORME ONAINDIA», DOCUMENTO DE LA CURIA DIOCESANA DE MADRID}

En el Arzobispado de Madrid, cuyos fondos documentales están ahora en el edificio de la calle Bailén (anejo a la Catedral de la Almudena), hay dos archivos que interesan a los historiadores: el «histórico», con documentos que se remontan al siglo XIV y que le fueron cedidos por el Arzobispado de Toledo al desgajarse Madrid de él en 1885 como nueva diócesis, y el «archivo vivo», con documentos más actuales y por ello más delicados o reservados. En éste último hay un legajo clasificado como "CARPETA "F", Serie IV", que contiene los datos de la «Información» del Obispado de Madrid; precisamente en ese legajo se halla un documento que destaca de los demás papeles y escritos que en él se encuentran, puesto que es de los pocos que se refieren a sucesos acaecidos fuera de la diócesis de Madrid-Alcalá, y parece redactado como réplica a un escrito laudatorio sobre la actuación del gobierno vasco, o como respuesta a una pregunta sobre ese tema. $\mathrm{Ni}$ en el mismo documento, ni en todo el legajo, ni en los legajos contiguos hay nota alguna que aclare el objeto o finalidad de ese singular manuscrito, pero parece en todo ser la respuesta a una consulta sobre la conducta del gobierno del PNV.

Como vimos en el epígrafe 3, al ser liberado por los políticos vascos Mons. Gandásegui había dicho: «La postura del PNV ha sido la de la Providencia, que ha salvado al pueblo vasco de una hecatombe de horrores y crímenes cometidos por los marxistas.» Sin embargo, y frente a este tipo de opiniones benevolentes

\footnotetext{
${ }^{27}$ Hablando de su situación y evolución a lo largo de la contienda, Múgica decía: «Entonces pudimos ver que el mal no era herencia exclusiva de un solo bando beligerante. Unos practicaban el mal por servir sus ideales anárquicos; otros hacían lo mismo, pretextando que obraban en nombre de Cristo.» Véase Mateo Múgica, Imperativos de mi conciencia. Buenos Aires, Liga de Amigos de los Vascos, 1945 , pp. 10-11.
} 
sobre la actuación del PNV en el País Vasco, haciendo respetar la ley y defendiendo a la Iglesia y a sus clérigos, en el Obispado de Madrid había sacerdotes que conocían y recordaban lo allí ocurrido en enero y marzo de 1937. Ysobre eso informaron en su propia diócesis a la autoridad encargada de recopilar las informaciones y datos sobre la persecución religiosa en la Espafía republicana durante la guerra civil. Ésa es la causa de que ese documento sobre lo ocurrido en Euzkadi aparece en el legajo de la «Información» del Obispado de MadridAlcalá sobre sus sacerdotes mártires en la guerra civil.

El mencionado documento tiene como título o encabezamiento «El fariseismo vizcaitarra", y su contenido parece más bien un contrapunto al «Informe Onaindía), por lo que le hemos dado el nombre de «Contrainforme Onaindía» debido a que su testimonio destruye la suposición de defensa del cristianismo, de la Iglesia y sus sacerdotes, y del orden social cristiano frente a la revolución marxista que -según el informe del canónigo vasco- tenía el PNV en el País Vasco. Su texto parece más un borrador o proyecto que un texto acabado; su letra es muy similar a algunas de las pocas existentes en los diversos papeles contenidos (además de las páginas extraidas de diferentes cuadernillos de la «Información») en el mencionado legajo "CARPETA "F", Serie IV» del archivo vivo del arzobispado madrileño. Debido al tiempo transcurrido desde entonces, no ha sido posible a este investigador identificar al autor a través de su letra; pero, aunque algunas fuentes han seffalado tres posibles autores, no hay pruebas suficientes para atribuirlo con algún grado de certeza moral a una persona concreta.

Según se va leyendo se pueden observar las numerosas diferencias de este «Informe» con el de Onaindía; no sólo en el tono (el del canónigo vasco es más profundo, sistemático y de redacción más cuidada), sino sobre todo en el contenido: el del canónigo es ideológico y razonado, y el de éste es sólo expositivo. Sin embargo, aunque el documento madrileño es notoriamente más flojo, es un verdadero «mentís» al contenido laudatorio que Onaindía aplicaba al PNV. Además, es un sentido recuerdo de las víctimas de los sucesos bilbaínos, así como una crítica acerba y sarcástica al gobierno vasco y al mismo PNV. Ese documento lo incluimos aquí como apéndice al final de este mismo estudio.

\section{TEMA DIFICIL, PERO HISTÓRICO Y NO CERRADO}

El tema de la persecución religiosa en la España de 1936 es un tema incómodo... para algunos que en eso pecan de pusilánimes. Algunos portavoces de partidos herederos de los que en aquel verano cometieron los crimenes de la persecución religiosa abominan de este tema, por lo que en nuestros días podría 
ser considerado «políticamente no-correcto». Sin embargo, y a pesar de ello, en estos últimos años el Papa está canonizando paulatinamente a sacerdotes, religioso, monjas y seglares (el gitano Pelé, por ejemplo) víctimas de la persecución religiosa en España, con el consiguiente escándalo de los sectores políticos y de prensa aludidos. Lo curioso es que -al contrario que la Iglesia universal- la Iglesia española intenta una vergonzante y defensiva coexistencia con esos sectores políticos y de opinión que le son (y seguirán siendo) radicalmente adversos. $Y$ en lo que a estos temas se refiere, la misma Iglesia española pasa por ellos como de puntillas y más parece avergonzada que heredera de lo que supone la secular tradición cristiana del martirio. Este hecho se puede comprobar en este mismo Congreso: siendo la persecución religiosa de 1936 el hecho histórico más importante y transcendental -junto con la desamortización de Mendizábal- de la Iglesia española en la Historia contemporánea, sólo hay prevista otra intervención para tratar este tema, sea cual sea el enfoque o interpretación que pueda dársele.

Sin embargo, y al margen de conveniencias u oportunismos (que de suyo siempre son coyunturales) la persecución religiosa en 1936 no sólo es un tema real y objetivo, sino que es histórico. Y por ello, la memoria debe recordarlo, y la ciencia histórica debe estudiarlo e interpretarlo. Sefialemos algunas líneas para su estudio.

En el plano de los hechos objetivos, los affos treinta de este siglo XX no se parecían en nada a esta última década, ni en España ni en ninguna parte del mundo. En aquellos críticos años, al igual que la mayoría de los que militaban en la causa de la República empezaron a autodenominarse (crojos», y por ello recibieron la solidaridad internacional de un sector de la sociedad occidental, muchos de los que militaban en la causa nacional (y, con ellos, la Iglesia española, cuyos supervivientes se veían empujados a encuadrarse en esa causa, puesto que la otra los había rechazado, perseguido y asesinado) empezaron también a autodenominarse "católicos», y por ello también recibieron apoyos, simpatías y solidaridad de otros sectores del mundo occidental, horrorizados por el holocausto de sacerdotes y seglares católicos asesinados en España por «odio a la fe».

En el plano de la ciencia histórica, hay autores que dicen que la Iglesia fue víctima y parte en la guerra civil. La realidad es que la Iglesia fue «víctima» en los inicios del conflicto, y por instinto de supervivencia se vio luego obligada a ser «parte». Y por lo mismo, ya entonces aparecieron numerosos apoyos y muestras de solidaridad con esa actitud. Las expresiones más laudatorias provenían de obispos pertenecientes a la comunidad iberoamericana de naciones, especialmente los episcopados paraguayo y chileno: «Siniestra y aterradora elocuencia de los hechos -decian los obispos chilenos- es lo que el mundo debe temer del comunismo que, dirigido desde Rusia, ha ejecutado en Espafia su pro- 
grama de acción". Los obispos de Filipinas, un Estado que entonces tenía una gran e influyente colonia española, decían: «Hacemos nuestra la causa sostenida por el generalísimo Franco [...] Nos alienta, empero, la esperanza en el próximo triunfo de la causa nacional. Nos parece ver en lontananza una España nueva, grande, libre, bañada con los resplandores de una religión mejor sentida.» De idéntico modo se expresaba la jerarquía eclesiástica de países católicos como Portugal e Irlanda.

Quizá por venir de un país protestante y ajeno a la tradición religiosa y cultural española, como es Gran Bretaña, tengan más valor las opiniones inglesas en contra de la actuación de la República española, tanto las de importantes políticos demócratas y conservadores (así, por ejemplo, Winston Churchill), como las de elementos de la jerarquía anglicana, como el arzobispo de Westminster. Churchill ${ }^{28}$ recordaba en sus «Memorias» el 36 español: «En España estaba manifestándose una perfecta reproducción del período de Kerensky en Rusia. [...] El ejército mantenía una considerable medida de cohesión. A la vez que la conspiración comunista, se elaboraba en secreto una contraconjura militar que había cobrado ya profundas raices. Ninguno de los dos bandos que conspiraban podía alegar, con justicia, títulos de legalidad, y los españoles de todas las clases tenían que pensar, ante todo, en la vida de España. Muchas de las garantías corrientes en la sociedad civilizada habían sido liquidadas por la infiltración comunista en un decaído gobierno parlamentario. Se producían atentados por ambas partes, y la pestilencia revolucionaria llegó a punto tal que los comunistas no titubeaban en asesinar a sus adversarios políticos en las calles o en sacarlos de sus lechos para darles muerte...) A su vez, Arthur Hinsley (arzobispo de Westminster) había escrito en septiembre de 1937: «Pronto nos dimos cuenta de que ésta no es una guerra civil cualquiera a favor de una dinastía o de algún régimen especial, ni tampoco -como falsamente se ha dicho-a favor de la democracia del pueblo español [...] Estamos a vuestro lado ${ }^{29}$.

En el plano de las corrientes o modas historiográficas, ciertamente la persecución religiosa es un tema que puede parecer «no conveniente» en ciertos

${ }^{28}$ Winston S. ChURChIL, Memorias. La Segunda Guerra Mundial, Orbis, Barcelona, 1989, vol. I, pp. 179-180; en esos párrafos se refleja el rechazo de la democrática sociedad británica de los años treinta respecto al comunismo y a la eliminación fisica que practicaba Stalin con los disidentes en Rusia, y a la que tnarxistas y anarquistas realizaban en España, en especial con los sacerdotes y fieles católicos. Por otro lado, es conocido que Churchill tuvo siempre un profundo afecto por los espafioles y su Ejército, en el cual combatió como voluntario contra los cubanos en 1898: por su heroísmo fue condecorado con la Cruz del Mérito Militar. Véase al respecto el libro de J. Pabón y SuÁrez de Uraina, Días de ajer. Historias e historiadores contemporáneos. Barcelona, Alpha, 1963, p. 145. También está recogido en M. Díz ALEGRiA, «La espléndida guerrita de los americanos», en Revue Internationale d'Histoire Militaire, n." 56, Madrid, 1984, p. 40.

${ }^{29}$ Boletin Oficial del Arzobispado de Zaragoza (1-diciembre-1937). 
ambientes y en algunos momentos, y que es un mal recuerdo que algunos pretenden borrar o ignorar para mantener una imagen pública de honradez, o de tolerancia y respeto democráticos. Pero eso es sólo cuestión de imagen, de propaganda; la memoria histórica no puede olvidar la realidad objetiva de los hechos, y es obligado recordarlos para que la crueldad y el horro ${ }^{30}$ que caracterizaron aquella feroz persecución jamás vuelvan a repetirse. No es justificable, bajo ningún aspecto y por ninguna causa, que el recuerdo de un holocausto -que en otros colectivos humanos se considera digno de respeto- no lo sea cuando se refiere al holocausto católico español de 1936, y se procure olvidar, justificar, negar o banalizar. Ningún crimen es jamás justificable ante la Historia ni ante la humanidad; y mucho menos cuando se comete sólo por rechazar ideas o por odio a la religión del asesinado.

Como historiadores debemos no sólo estudiarlo y recordarlo, sino interpretarlo con rigor en el contexto social e histórico en el que se produjo, sin caer en reduccionismos ni en formulaciones simplistas o frívolas, que nada dicen y nada explican. Y debemos hacerlo reconociendo lo que entonces hubo de habitual y de coyuntural, admitiendo los aciertos y errores de los que fueron sus víctimas, $y$ la responsabilidad de quienes fueron los agresores mientras hablaban de democracia y practicaban la tiranía y la barbarie intolerante. Aquella bárbara persecución fue tan atroz que no puede compararse con ninguna de las que posteriormente se han dado, quizás con la excepción de la que los Jemeres rojos efectuaron en Camboya.

Sólo entendiendo esto se podrá comprender que la Iglesia se alineara con uno de los bandos contendientes, pues estaba forzada a ello por las circunstancias: elegir lo contrario era impensable, y no hacerlo hubiera sido suicida. EI estudio del holocausto católico español de 1936 debe hacerse seria y concienzudamente, y hay que realizarlo partiendo de la realidad objetiva. Esa es una tarea para los historiadores que aún está por realizarse en el conjunto de Espa-

\footnotetext{
${ }^{30}$ De aquel horror y ferocidad no se libraron las mujeres, a pesar de que en aquellos años eran consideradas de forma muy diferente a la de nuestros días: muchas fueron fusiladas por ser monjas, no espías, ni soldados, ni siquiera por "colaboracionismo" o connivencia con el enemigo. Mons. MoNTERo, además de su citada obra más conocida y clásica, tiene otra titulada Holocausto de las esposas de Cristo. En élla trata del asesinato de muchas religiosas destacando que ni su "condición femenina fue coto para la furia terrorista de aquel períodon; así, las dos primeras monjas fusiladas en Madrid lo fueron el día 20 de julio de 1936 en el barrio de Ventas: nueve balazos tenía cada una. Abundando en este mismo aspecto, una de las (informaciones» enviadas al Obispado de Madrid, y que se encuentran en el ya citado legajo, relata que un grupo de milicianos cogió prisioneras a varias Hijas de la Caridad para fusilarlas. Al lievarlas al paredón, algunos miembros del pelotón recriminaron a un compañero, nacido en aquel barrio y que había estudiado en el colegio de las religiosas, diciéndole: «jDesgraciao! ¿Vas a matar a ésa que te enseñó a leer? Los demás, tras rechazar al miliciano desagradecido, alinearon a las diez monjas contra una pared y las fusilaron de inmediato.
}

Actas del I Congreso de Historia de la Iglesia y el Mundo Hispánico Hispania Sacra, 52 (2000) 
ña: la persecución religiosa en 1936 sigue siendo todavía un tema abierto y actual... porque la mentalidad y el odio que la generaron perduran todavía. Por eso, cuando José Luis Alfaya publicó en 1998 su tesis doctoral Como un río de fuego. Madrid 1936, no tuvo ninguna publicidad en los medios de comunicación, y apenas llegó su noticia al público. No es raro: ni siquiera los obispos de Espafia han apoyado la asociación «Hispania Martyr, siglo XX» desde que se creara en 1970.

Incomprensiblemente, el clero espafiol (que cuantitativa y socialmente fue la primera víctima de aquellos trágicos sucesos) parece haberlo olvidado; tal actitud es peligrosa, porque no nace del perdón cristiano -que perdona a los verdugos sin olvidar a sus hermanos martirizados- sino que es más bien fruto de la ignorancia o de la banalización del martirio, lo que es anticristiano por el simple hecho de que el mismo Jesús fue el primer mártir de su propia doctrina. Sin embargo, no lo han olvidado ni las familias españolas que entonces perdieron a algún pariente, ni tampoco la Iglesia; no hace muchos años que el Papa, a este respecto, decia:

«En nuestro siglo han vuelto los mártires con frecuencia ignorados, casi "soldados desconocidos' de la gran Causa de Dios [...] Conviene que las Iglesias locales hagan todo lo posible por no perder el recuerdo de quienes han sufrido el martirio, recogiendo para ello la documentación necesaria. Esto debe tener un sentido y elocuencia ecuménica. El ecumenismo de santos y mártires es, quizás, el más convincente $[. ..] 3^{31}$.

Últimamente se ha puesto de moda una frase: «Los pueblos que olvidan su historia corren el riego de volver a repetirla.» Personalmente desconozco su validez, pero no sé de nadie tan ruin como para desear que aquella situación vuelva a repetirse; y sin embargo, la presencia de crucifijos en las aulas ha vuelto a levantar este mismo año 1999 una viva y encendida polémica en la opinión pública... porque aquellos antagonismo y prejuicios perduran todavía en nuestra época de falsa tolerancia. ¿Es que no basta ya de odio?

\section{APÉNDICE (TRANSCRIPCIÓN DEL TEXTO MANUSCRITO)}

\section{EL FARISEISMO VIZCAITARRA. Cuaresma y Semana Santa en Euskadi.}

Difíciles y prefiadas de tribulaciones fueron los largos meses que pasaron en Bilbao los sacerdotes y religiosos que tuvieron la mala fortuna de soportar allí la dominación del titulado gobier-

31 JUAN Pablo II, Carta Apostólica «Al llegar el III Milenio», n. 37. 
no de Euskadi. Atraídos por el señuelo de la religiosidad de los nacionalistas vascos, se habían refugiado en la capital vizcaína varios centenares de sacerdotes, la mayoría de la diócesis de Santander, algunos asturianos y hasta una veintena oriundos de otras diócesis y a quienes había sorprendido el Movirniento en algunos de los balnearios de la provincia de Santander y que estaban en la capital de la Montaña asistiendo a los cursillos de verano organizados por la Universidad Católica de Madrid.

Se había corrido la voz de que el gobiemo vasco tenía interés primordial en poner a salvo a las personas religiosas y, en busca del ansiado pasaporte, allá se fueron toda esta multitud de desgraciados, huyendo de las persecuciones y atropellos de que habian sido víctimas en las provincias de Asturias y Santander varios companeros suyos, algunos de los cuales fueron quemados vivos y otros fusilados y bárbaramente martirizados.

La primera desilusión de estos refugiados en Bilbao fue saber que de allí no habian podido salir las personalidades religiosas nacidas en Vizcaya o que en ella desempeñaran sus ministerios, a pesar de la influencia que naturalmente tenian con los dirigentes de la política nacionalista. Únicamente se sabía que se les había concedido el pasaporte a algunos afiliados al nacionalismo, quienes, cobardes y traidores a sus convicciones, abandonaban a sus amigos en las horas trágicas. No obstante, los forasteros creyeron en las promesas que casi a diario y de un modo semioficial se les hacían de que Aguirre y sus acb́litos estaban interesados en ponerlos a salvo para evitar, según manifestó repetidas veces el Consejero de Gobernación, Monzón, la responsabilidad histórica y moral que caería sobre el gobierno de Madrid si aquellos sacerdotes forasteros fuesen víctimas de las agresiones inconscientes del pueblo.

Y no se crea que era tan fácil ver a Monzón, de quien dependía la concesión de pasaportes. En el edificio de la Sociedad Bilbaina, donde se había instalado el Departamento de Gobernación, había que explicar primeramente a los guardias que había en la puerta a lo que se iba; luego, en el piso principal, había que llenar un volante expresando a quien se quería ver y el objeto de la visita; y, cuando ya se creía que sería cosa de poco más o menos tiempo ser recibido por el Consejero, salía un muchachuelo que les decía que le manifestasen sus deseos, que él, que era uno de los secretarios del Sr. Gamendía, se los expondría a éste, quien a su vez se los trasiadaría al señor Luisa de quien era secretario particular, para que el Sr. Luisa, Secretario general del Departamento, los pusiese en conocimiento de S.E. el Sr. Consejero. Y en este refriego se pasaban los días, y aquellos pobres sacerdotes no lograban hablar más que con algún ordenanza o con el consabido mocoso, secretario del secretario del Secretario del Departamento.

$\mathrm{Y}$ así vieron cómo desde el 30 de noviembre se sucedieron las expediciones organizadas por la Cruz Roja sin que en ellas tuviesen cabida más que las familias de los paniaguados, y asi llegaron al horroroso 25 de enero en que las turbas, sin que nadie intentase contenerlas, asaltaron las cárceles y dieron bárbara muerte a 205 desgraciados, entre ellos a trece sacerdotes, en el convento de los Ángeles Custodios habilitado como prisión. Esta ignominiosa agresión, de la que tanto se ha hablado y escrito, que no tuvo para Monzón más comentario que aquellas palabras hipócritas "(Qué dirán en Inglaterral», no hizo mella en los gerifaltes nacionalistas ni les conmovió para conceder el pasaporte a los sacerdotes y religiosos, de quienes ya se decía públicamente que habían de ser pronto víctimas del populacho.

Nada hacian para contrarrestar este ambiente los mandones, sino que parece que se complacian en mantenet vivo el fuego de las persecuciones contra las personas sagradas, como lo prueban los incidentes a que dieron lugar, durante aquellos tristes días de la Cuaresma de 1937, aquellos meses de Febrero y Marzo en los que se repetían las detenciones de sacerdotes por los motivos más fútiles. Una tarde fueron detenidos trece sacerdotes en la sacristía de la parroquia de San Nicolás, a donde concurrian diariamente bien a rezar las horas canónicas, o simplemente a charlar de la situación; a los pocos días, en una modesta casa de huéspedes de la calle de la Amnistía, con

Actas del I Congreso de Historia de la Iglesia y el Mundo Hispánico Hispania Sacra, 52 (2000) 
el pretexto de que alli se conspiraba, fueron detenidos una docena de personas inofensivas, entre ellas cinco sacerdotes santanderinos, cuando tranquilamente charlaban de los sucesos de actualidad, a la vez que otro companiero suyo, ya septuagenario, fue detenido al salir de decir misa de la parroquia de San Francisco por unos individuos que se decian policjas de Santander, sin que las autoridades hicieran gestiones para saber quiénes eran los aprehensores ni por buscar al detenido, de quien no se volvió a saber nada.

También un sábado de aquella cuaresma, al terminar de oír confesiones en la iglesia de San Vicente, fue detenido y llevado a los calabozos de la Bilbaina el anciano y popular escritor jesuita P. Remigio Vilarifio, quien permaneció en aquellas mazmorras largos días por el solo motivo, según se dijo, de ser el autor de las máximas que, con el título «Un minuto de filosofia», se insertan en las hojas diarias del Calendario del Corazón de Jesús y que, de tener algo por lo que se pudiera perseguir a su autor, estaban escritas e impresas mucho antes de haber estallado el Movimiento; y, finalmente, por aquellos días se celebró en la Audiencia, ante el tribunal popular, la vista de la causa contra el benemérito jesuita $P$. Enrique Herrera Oria y varios caballeros más, a quienes se les acusaba del enorme delito de haberse querido embarcar en El Anchove, cansados de tantas promesas vanas como se les hicieron para concederles el pasaporte, atrayendo la atención de los bilbaínos aquel juicio por el aparato con que se le revistió, y del que salieron condenados todos los encausados, algunos a cadena perpetua y el P. Herrera a doce o catorce años de presidjo.

Como estos atropellos podrian citarse otros muchos, pudiéndose decir que la predicación era casi nula en Bilbao, pues los sacerdotes no se atrevían a subir al púlpito por temor a que cualquier palabra, o cualquier concepto, pudiese ser falsamente interpretado y fuese motivo para que fuesen detenidos.

Y así llegó el Domingo de Ramos, dia 21 de marzo. Desde por la mafiana se había corrido en Bilbao la voz de que se iba a realizar un importante servicio policiaco en Las Arenas. Se hablaba de un complot tremebundo en el que estaban comprometidas todas las familias bien que tenían su residencia en Las Arenas, Neguri y Algorta; se decía que había en proyecto una especie de marcha sobre Bilbao, y hasta se llegó a decir que se temia un desembarco de tropas facciosas en Las Arenas. Lo cierto de ello es que desde las diez de la mañana quedó interrumpida la comunicación con los pueblos limítrofes de la Ria, que los tranvías de Las Arenas y Algorta, así como los automóviles particulares, no podían pasar de las cercanias de la capital, y que varios centenares de automóviles oficiales establecieron un cordón impenetrable en Las Arenas y en Algorta, a la vez que todas las embarcaciones de que se pudo echar mano establecieron una especie de bloqueo por aquellas playas.

La gente estaba preocupada en Bitbao y no faltaron personas prudentes que, ante el temor de posibles sucesos, se retiraron a Archanda y a Begona, o a los montes circundantes. Bien pronto se aclaró todo: en las primeras horas de la tarde se supo que todo aquel aparato bélico había tenido por objeto detener a los fieles que, al salir de misa en las parroquias de Las Arenas y de Algorta, iban en grupos o sencillamente en parejas: 117 personas, todas ellas conocidísimas por sus ideas pacifistas y algunos sacerdotes, fueron detenidas y encerradas en los locales del Club Náutico del Abra.

Al día siguiente, los periódicos dieron la relación de los detenidos y las multas que les habian sido impuestas, corroborando así la opinión que todo el mundo tenía de que las detenciones arbitrarias que se venian sucediendo no tenian más objeto que sacar pesetas para poder pagar la nómina de los miles de zánganos que sesteaban satisfechos en los diversos departamentos ministeriales.

No se daban cuenta, o no querían dársela, aquellos cretinos del ridículo que corrian, y asi el melogámano (sic) de Aguirre, en la exaltación de su persona, llegó el Viernes Santo, después de

Actas del I Congreso de Historia de la Iglesia y el Mundo Hispánico

Hispania Sacra, 52 (2000) 
los Divinos Oficios, a indultar solemnemente a trece detenidos, previo el cambio de las cintas moradas de los expedientes por otras blancas... Así, como un hombrecito, como si de verdad fuese jefe de un gran Estado independiente.

Menos mal que ya faltaban pocos dias para que las tropas del invicto general Mola acabaran con las trapacerias de aquella gavilla de pícaros, y con la hipocresía de las histéricas «emacumes» que hacian novenas a Sabino Arana, aquel cretino integral que tuvo la avilantez de telegrafiar a MacKinley cuando fue destruida a mansalva nuestra escuadra en Santiago de Cuba, y cuyo odio a Espana se ha transmitido a los vizcaitarras.

ARIEL

Actas del I Congreso de Historia de ia Iglesia y el Mundo Hispánico Hispania Sacra, $52(2000)$ 